Veterin. Inst. d. Fachabteilung d. Fischerei u. Tierzucht, Unir. Hiroshima (Vorstand: Prof. Y. TStJI) u. Anat. Inst. d. Med. Fak. Iniv. Okayama

(Torstand: Prof. M. SEKI).

\title{
Methode zur sehr elektiven und sehr distinkten Darstellung der Mitochondrien durch Versilberung.
}

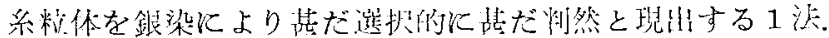

\section{Shunsaku FUJII 漛 非 俊 策。}

(Eingegangen am 4. Oktober 1956.)

Ws gibt schon über zehn ausgezeichnete Nethoden zur Darstellung der Mitochondrien mit Farbstoffen, aher wir haben bisher kaum gute Versilberungsmethoden. Friber beobarhtete KOLNER (1916) nach der CA.JALschen Cran-Silbermethode haüfig neben dem GOLGI-Apparat auch rersilberte Witochondrien. Ws gelang TOMITA (1941) Mitochondrien nach seiner Gelatine-Silbermethode darzustellen. MATSUDA (1936) konnte nach einer modifizierten TOMITAschen Methode Mitochondrien in den Pancreaszellen färban, und FUKUDA (1940) in den kultivierten Fibrocylen. Aber nach solchen Silbermethoden schwärzen sich neben den Vitochondrien sehr oft andere reduzierend wirkende Gebikde. Der Verfasser vorliegender Mitteilung konnte die Mitochondrien nach einer neven Methode sehr elektiv und sehr distinkt darstellen. Danach behandelt man zurol die Gewebsschnit.e mit Goldchlorid und erst danach imprägniert man sie mit silbernitrat.

\section{Verfahren der Versilberung.}

1. Win frisches Gewebsstïckchen wird mit REG-AUJ)scher BichromatFormalinlösung für 2 Tage fixiert und dann für 5 Tage in $3 \%$ ige Bichromatlösung gelegt. Während dieser Zeit wird die Lösung täglich ernenert. Als Fixierungsmittel wurden außer der RLGACDschen Flüssigkeit noch ORTHsche Lösung, 10\%iges neutrales Formatin, 10\% iges Formalin und ZENKER, HELLY- und BOUINsche lösung durchprobjer. Die REGATDwhe Flissigkeit crwies sich aber als die beste, als nïchstheste folgten 10\%iges Formalin und 10\% iges neutrales Formalin, während andere Flussigkeiten weniger gute Resultate gaben.

2. Gründliches Auswasthen in destilliertom Wasser für 1 Tag.

3. Entwässern and Einbetten in Paraffin wje gewöhnlich. Schneiden in Schnitte von $3^{-5} / \ell$ Dicke. Kleben der Schnitte auf dem Objektglas.

4. Ist das Bichromat aus den Schnitten nicht genügend ausgegangen, so wäscht man sie vor der Fïrbung mit $2-5 \%$ iger Bicarbonatlösung ans.

5. Narh kurzer Abspïlung fiillt man die Oberflärhe des mit den 
Schnitten aufgeklebten Objektglases 3-5 Minuten lang mit einer sehr verdünnten Goldchloridlösung. Die Goldchloridlösung wird bereitet, indem man 3 Tropfen einer $1 \%$ igen Goldchloridlösung in $5 \mathrm{cc}$ destillierten Wassers löst.

6. Die Goldchloridlösung wird abgegoßen, und das Objektglas wird ohne Abspülung mit. Wasser mit einer 1-2\%igen Silbernitratlösung mit einem Zusatz von gleicher Menge 1\%iger Gelatinelösung gefüllt und bei $37^{\circ} \mathrm{C} 3-4$ Minuten lang liegen gelassen.

7. Nach Abgießen der Silbernitratlösung wird das Objektglas ohne Answaschen mit Wasser mit einer Hydrochinonlösung, bestehend aus 0.5\%iger Hydrochinonlösung und $1 \%$ iger Gelatinelösung zu gleichen Teilen, gefüllt und bei $37^{\circ} \mathrm{C}$ für $1-2$ Minuten lang liegen gelassen. Inzwischen beohachtet man die Schnitte unter dem Mikroskop. Zur Beohachtung iiberträgt man das Objektiglas, sobald als im Cytoplasma sehwarze Granula auftreten, ins Wasser.

8. Gründliches Auswaschen der Schnitte, dann Entwässern und Finschließen in Kanadabalsam.

In den gelungenen Präparaten tingieren sich die Mitochondrien sehr scharf schwarz mit violettem Ton. Die Cytoplasmagrundsubstanz färbt, sich entweder schwach gelblich oder blaßriolett. Der Kern färbt sich kaum, nur das Kernkörperchen tritt violettschwarz gefärbt auf. Zuweilen wird die Cytoplasmagrundsubstanz intensiv gelbhraun gefärbt. Dabei heben sich die ebenfalls gelbbraun gefärbten Mitochondrien nicht dentlich ab. Eine solche Folge tritt leicht ein, wenn eine nicht frische Silbernitrat- und Hydrochinonlösung angewandt wird. In einem solchem Falls ist eine Differenzung der Färbung mit, einem Gemisch von 1\% iger Ferricyankaliumlösung und einer 5\%igen Natriumhyposulfitlösung im Verhältnis $1: 10$ zu empfehlen. Zur Nachfärbung des Kerns eignet sich Safranin oder Kernechtrot.

\section{Befunde der Mitochondrien in verschiedenen Zellen nach dieser Versilberungsmethode.}

Im folgenden sollen die nach dieser. Versilherungsmethode dargestellten Mitochondrien in verschiedenen Zellen der erwachsenen Maus besprochen werden.

\section{Submandibulardrüse.}

Über die Mitochondrien der Submandibulardriise liegen viele Mitteilungen vor, wie z. B. ron SCHLITTZE (1911), TAKAGI (1925) und SEKINF (1937). Nach meiner Versilberungsmethode erscheinen die meisten Mitochondrien in den Druisenzellen des sezernierenden Teils, wie in Abb. 1 gezeigt ist, in Form von langen, dicken und of an einem Knde verdickten Stäbchen mit einer leichten Krümmung. Körnige Formen sind wenig. Durch genauerer Beobachtung wird bestätigt, daß die stäbehenförmigen 


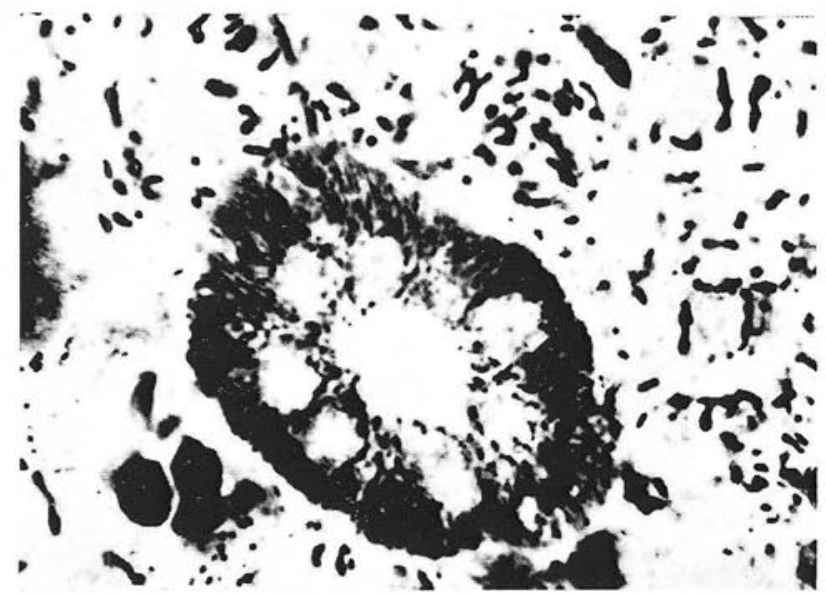

Abb. 1. Submandibulardrüse. Ein Querschnitt des Streifenstückes in der Mitte der Abbildung. $900 \times$.

Mitochondrien mehr im Basalteil und die granulären Formen mehr im apikalen Teil der Zellen vorhanden sind. Sie ordnen sich nicht sehr regelmäßig in den Zellen.

In den Zellen des Streifenstückes ordnen sich dagegen schlanke fadenförmige Mitochondrien von der Zellbasis senkrecht nach oben in longitudinaler Richtung und bilden sog. Basalstreifen. Die Mitochondrien sind auf der lateralen Seite des Kerns stäbchenförmig und verhältnismäßig weniger vorhanden, und über dem Kern körnig in Form und noch weniger an Zahl.

\section{Fundocorpusdrüsen des Magens.}

Über die Mitochondrien in den Zellen der Fundocorpusdrüsen gibt es eine Mitteilung von EKLÖF (1914), OKANISHI (1933), INOUE (1936) u. a. m. Die Mitochondrien der Hauptzellen werden nach meiner Methode wie in Abb. 2 dargestellt. Sie sind zum größten Teil fadenförmig und etwas dick oder schwach gekrümmt. Mitochondrien von Stäbchenform kommen wenig vor. Im Apikalteil der Zellen finden sich granuläre, ringförmige, perlenschnurartige Mitochondrien in geringer Zahl.

In den Belegzellen drängen sich verhältnismäßig grobe Granula. Diese Granula wurden von ZIMMERMANN (1898) als Sekretgranula und von SCHLUTZE (1911) und EKLÖF (1914) als Mitochondrien bezeichnet.

\section{Duodenum.}

Es gibt auch viele Untersuchungen über die Mitochondrien in den Epithelzellen des Duodenums. Danach sollen die Mitochondrien unter dem Kern körnig und über dem Kern stäbchenförmig sein. Auch in meinen versilberten Präparaten sind die Mitochondrien, wie es in Abb. 3 dargestellt 


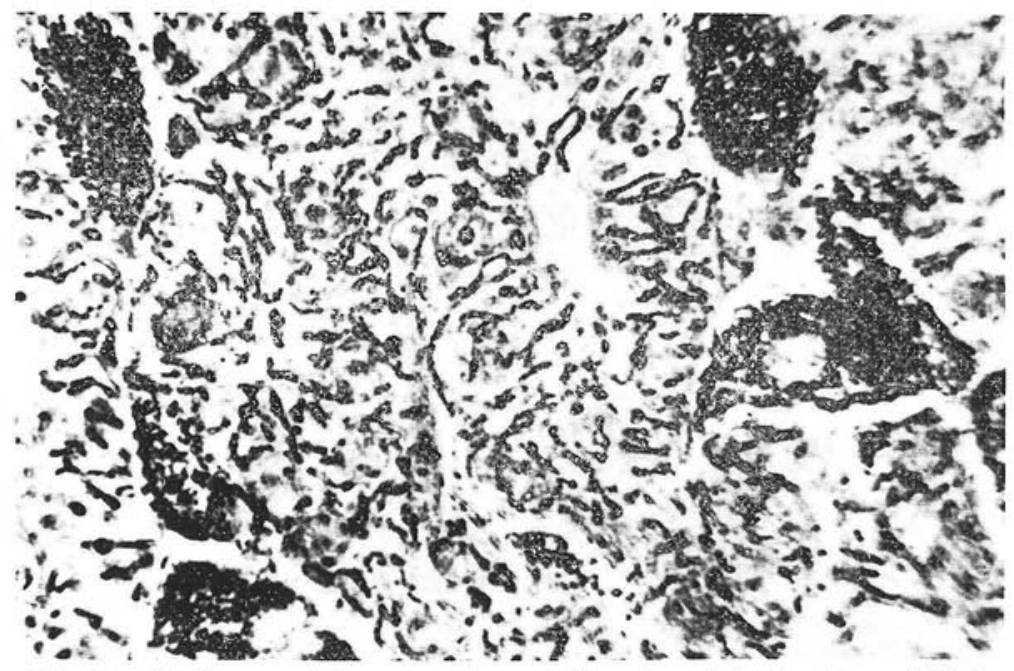

Abb. 2. Fundocorpusdrüsen des Magens. Haupt- und Belegzellen. $900 \times$.

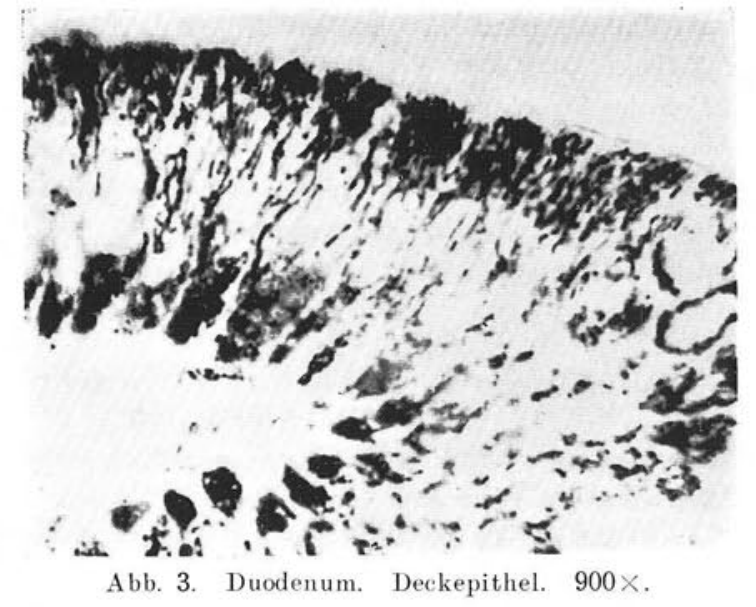

ist, im supranuclearen Teil stäbchenförmig und longitudinal und parallel vorhanden, dagegen sind sie im infranuclearen Teil körnig und drängen sich dicht. Im Bereich des GOLGIschen Apparates oberhalb des Kerns existieren fast keine Mitochondrien.

In den Epithelzellen des Endabschnittes des Dudenums vermehren sich die körnigen Mitochondrien im supranuclearen Teil der Zellen und die stäbchenförmigen im infranuclearen Teil derselben (Abb. 4).

In den Epitheizellen der Krypten (Abb. 5) sieht man eine Ansammlung von körnigen Mitochondrien nahe dem Scheitel der Zellen. Faden- und 


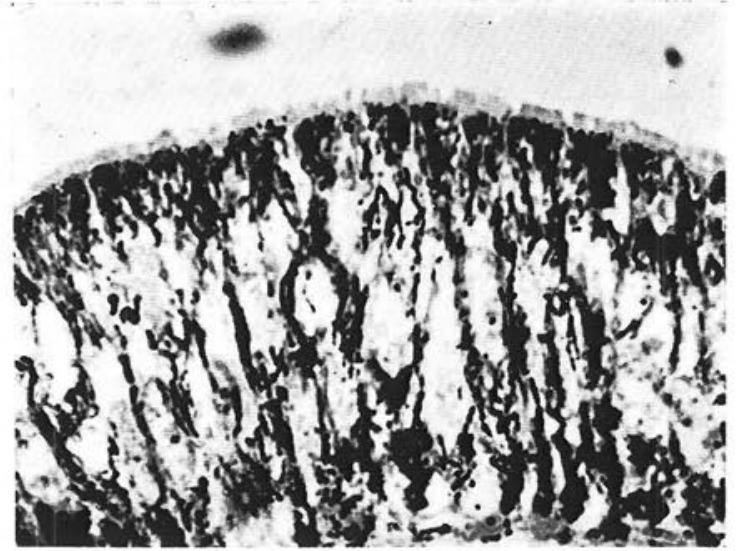

A bb. 4. Endabschnitt des Duodenums. Deckepithel. $900 \times$.

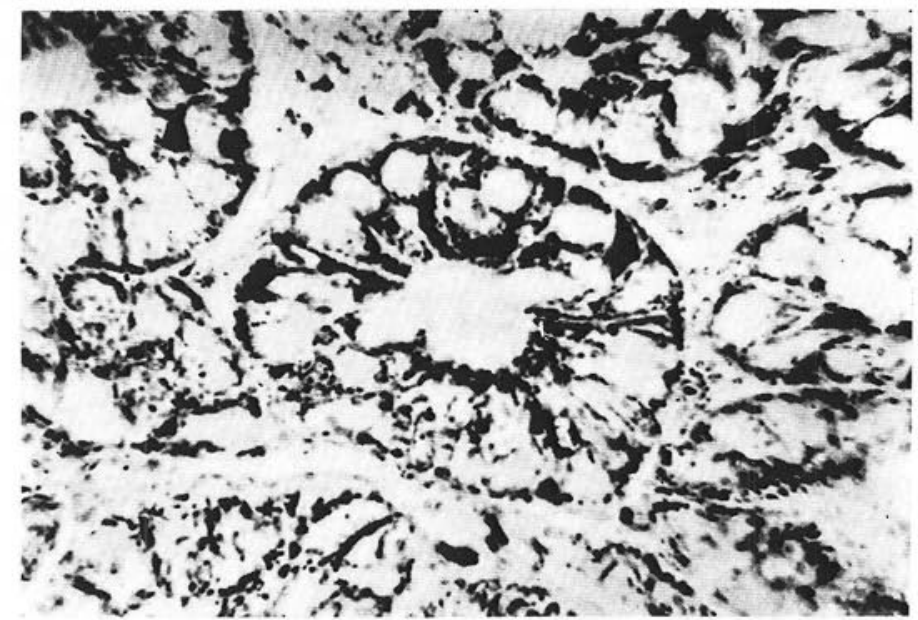

Abb. 5. Duodenum. Darmkrypten. $900 \times$.

stäbchenförmige Mitochondrien sind hier selten.

Die Granula der PANETHschen Zellen treten mehr oder weniger geschwär"zt auf.

Die Mitochondrien treten in den Zellen der BRUNNERschen Duodenaldrüsen sehr distinkt zutage (Abb. 6). Die meisten von ihnen sind stäbchenoder fadenförmig. Die länglichen Formen ordnen sich longitudinal und parallel.

4. Blinddarm.

Die Mitochondrien in den Epithelzellen sind, wie in Abb. 7 dargestellt 


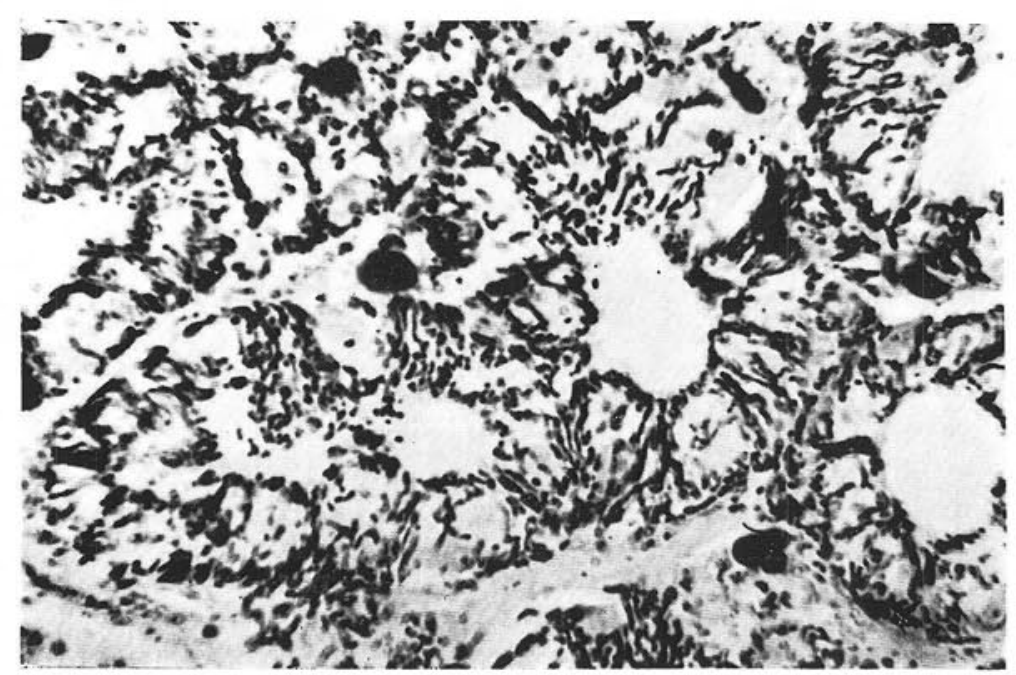

Abb. 6. BRUNNERsche Duodenaldrüse. $900 \times$.

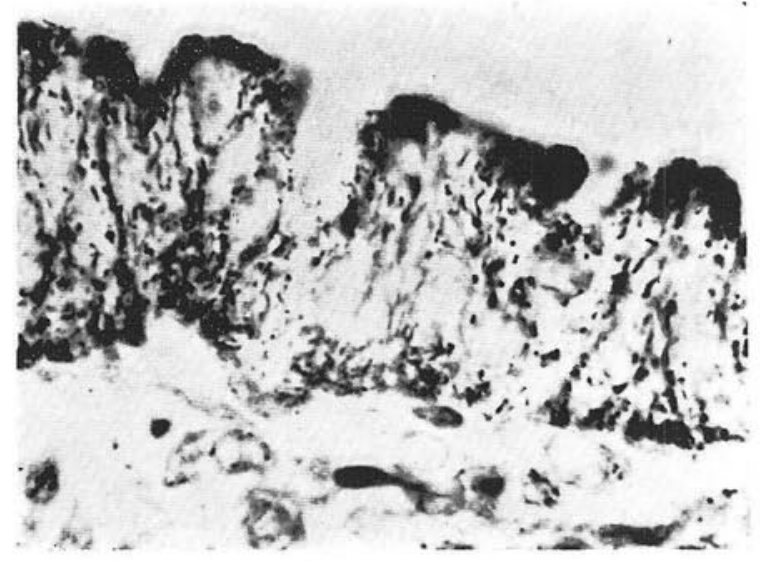

Abb. 7. Blinddarm. Deckepithel. $900 \times$.

ist, zumeist stäbchen- oder fadenförmig und weniger an Zahl vorhanden als in den Zellen des Duodenums.

\section{Pancreas.}

Weil die Mitochondrien in den Pancreaszellen groß und leicht darstellbar sind, ist darüber eine große Literatur vorhanden. Wir finden z. B. die Arbeit von BENSLEY (1911), SCHLUTZE (1911), MISLAWSKY (1911, 1913), ARNORI) (1912) แ. a. Die Abb. 8 zeigt die Mitochondrien in den Pancreaszellen nach meiner Methode. Sie sind von verschiedenen Formen: 


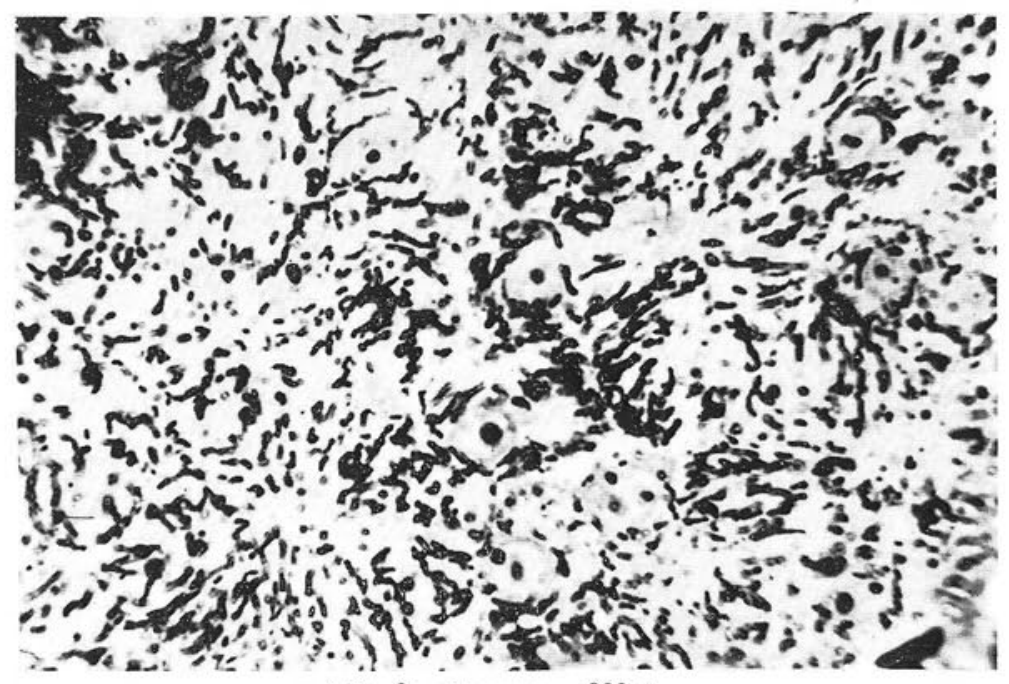

Abb. 8. Pancreas. $900 \times$.

faden- und stäbchenförmig, stäbchenförmig mit einer Verdickung am Ende oder an der Nitte und gerade und gekrümmt. In allgemein liegen lange Mitochondrien in dem Basalteil der Zellen und kurze mehr im Scheitelteil derselben. Die Mitochondrien richten sich nach dem Drüsenlumen hin und ordnen sich parallel. An einer anderen Stelle desselben Präparates sind aber die meisten Mitochondrien, wie man es in Abb. 9 sieht, stäbchen-,

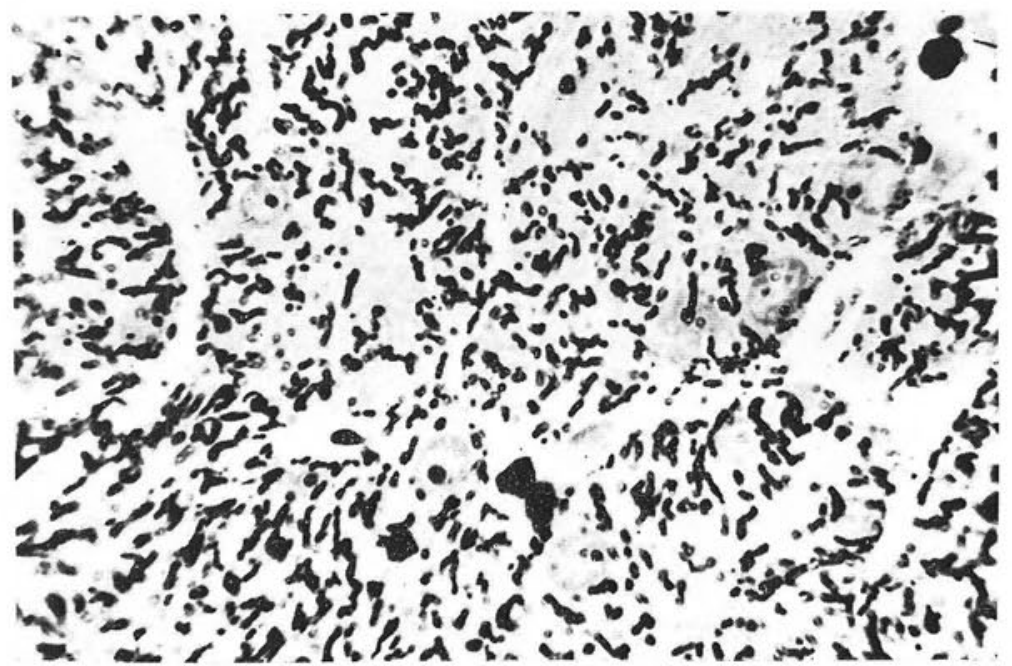

Abb. 9. Pancreas. $900 \times$. 
hanter-, komma-, und perlschnurförmig und körnig, dagegen sind langfadenförmige wenig zu finden. Man sieht also, daß je nach der Funktion der Zellen sich die Form und Zahl der Mitochondrien leicht und mannigfaltig verändern. Bei, einer näheren Beobachtung in der Abb. 8 und 9 konstatiert man, daß das eine oder beide Enden der Mitochondrien oft schwächer geschwärzt, daß ferner schwächer geschwärzte ringförmige Gebilde von gleicher Größe vielerorts zwischen den Mitochondrien zu sehen sind. Es handelt sich vielleicht um Sekretionsgranula.

\section{Leber.}

Über die Mitochondrien in den Leberzellen der Maus gibt es eine genaue Arbeit von NOEL (1923). Danach sind die Mitochondrien in den Leberzellen in der Umgebung der Centralvene des Läppchens zum größen Teil im Ruhezustand und schlank von Gestalt, dagegen erscheinen sie in der Aktivitätsrandzone des Leberläppchens zumeist keulen- bis kugelförmig. In Abb. 10 ist ein Stück aus der Umgebung der Centralvene gezeigt. Stäbchenförmige Mitochondrien sind mehr vorhanden. Im Gegensatz dazu sind

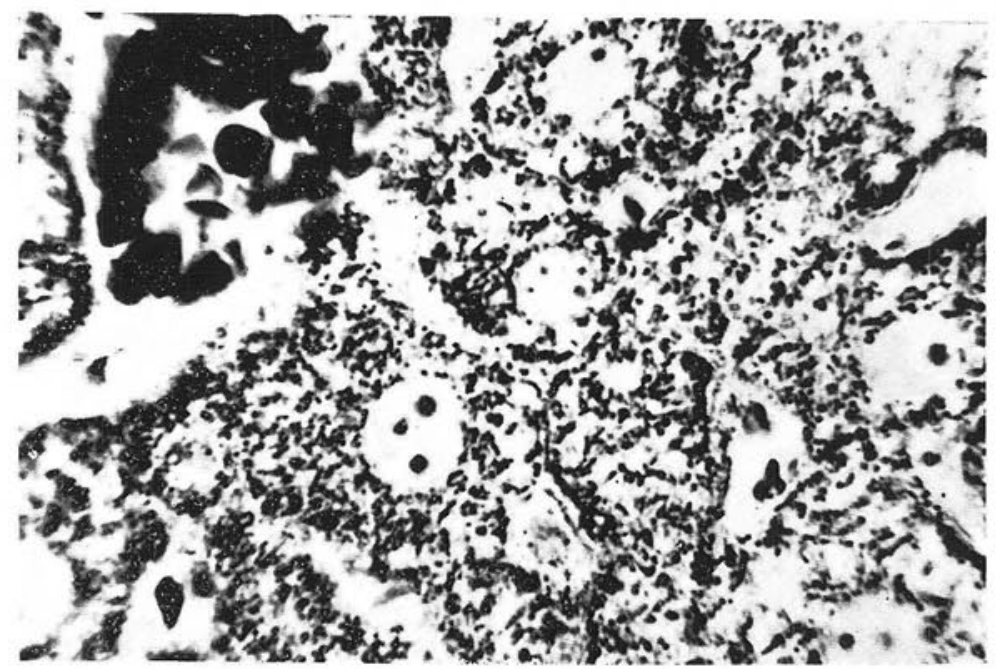

Abb. 10. Leber. Aus dem Centralteil des Läppchens. $900 \times$.

die Mitochondrien in Abb. 11 von dem peripheren Teil des Leberläppchens fast alle grob körnig. Die Mehrzahl von ihnen lagert sich in der Randzone des Zelleibes. Außer den Mitochondrien sieht man im Cytoplasma zahlreiche schwach gefärbte Körnchen, die wahrscheinlich lipoidhaltige Granula sind. 


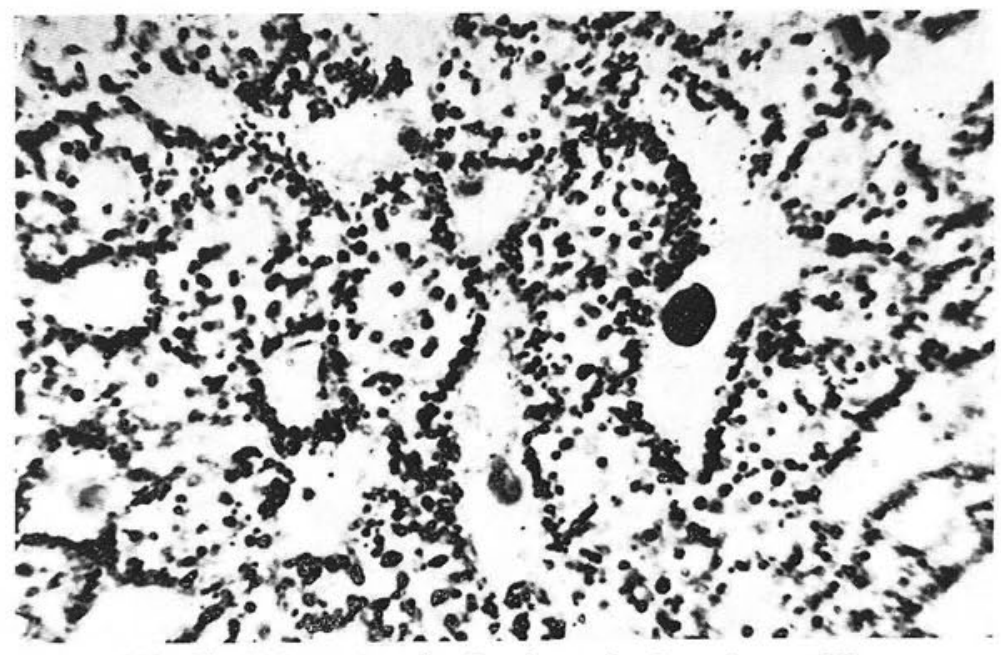

Abb. 11. Leber. Aus der Randzone des Läppchens. $900 \times$.

7. Niere.

Aus der Literatur über die Mitochondrien des Harnkanälchens sind z. B. die Mitteilungen von BENDA (1903), KOLSTER (1911), MIYOSHI (1936) und SUNAGA (1955) zu nennen. Die sog. Nierenstäbchen in den Zellen des Hauptstückes des Harnkanälchens sind seit BENDA als Reihen der Mitochondrien angenommen. Dies ist ganz klar in unserer Abb. 12 veranschaulicht.

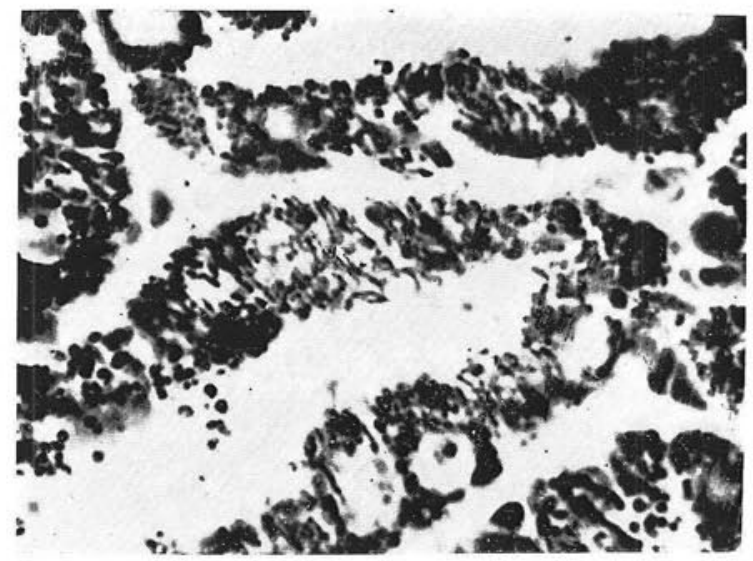

Abb. 12. Haupstück der Niere. $900 \times$.

\section{Uterus.}

Über die Mitochondrien der Epithelzellen des Uterus sind Berichte 
von KATO (1929), OGAWA (1934) u. a. vorhanden. In Abb. 13 ist das Uterusepithel einer Maus in der Zeit 2 Tage nach der Geburt gezeigt. Die Mitochondrien sind meistens stäbchen- oder fadenförmig und verdicken sich häufig am Ende. Körnige Formen sind wenig. Die Verteilung der Mitochondrien oberhalb und unterhalb des Kerns ist nahezu die gleiche.

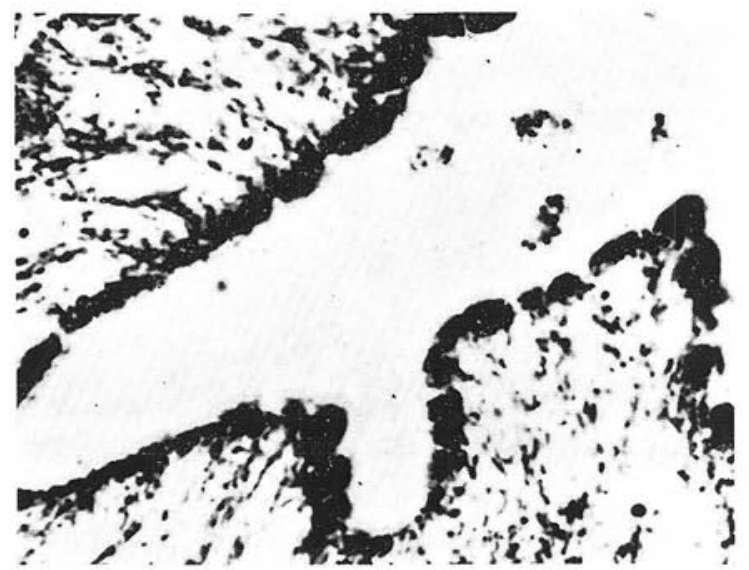

Abb. 13. Uterus, 2 tage nach Geburt. $900 \times$.

\section{Bläschendrüse.}

Die Mitochondrien in den Zellen dieses Organs erscheinen meist zierlich faden- und stäbchenförmig, жwischen diesen verteilen sich körnige Formen in geringer Zahl (Abb. 14).

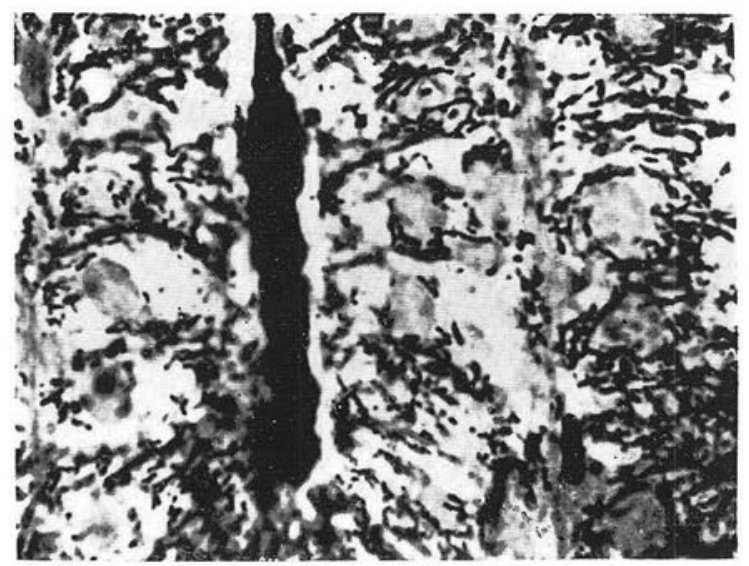

Abb. 14. Bläschendrüse. $900 \times$. 


\section{Auswertung der Ergebnisse.}

Früher zog TANAKA (1927) etwas zwanzig Versilherungsmethoden zur Darstellung ron Zellgramula in Betracht und wies auf die Möglichkeit del Versilberung rersehiedener Gebilde in Crtoplasma hin. Nach meiner Methode, wonach man das Gewebe vor allem mit der RWGAUDschen Flüssigkeit fixert und dessen Sichnite nach der Vorbehandlung mit einer verdïnnter foldchloridlösung versilbert, werden solche Gebilde dargestellt. die aus ihrer Form. Zahl und Verleilung im Zelleih wenigstens zum größten Teil als Mirochondrien aufzufassn sind. Sie sind ganz anderes als die Granula, welche KON (1937) nach seiner Methode in Benutzung ammoniakalischer Silherlösung versilberte. Die Methoden ron MATSCDA (1936) und TOMITA (1941), nach welchen das Gewebe in der osmiumsäurehaltigen CHAMPYschen oder FLWMMINGshen bösung fixiert and mit einer Gelatine-Silberlösung behandelt wird, schwärzt nicht nur die Mitochondrien, sondern auch den GOLAI-Apparat oder die Lipoidgranula.

Der einzige Nachteil meiner Wethode ist, daß die nach ihr geschwäraten Mitochondrien verglichen mil denen nach der HEIJliNHALNschen Eisenhämatoxylinmethode 1. a. bei Benutzung con Farbstofien mehr odes weniger dick erseheinen. Je konzentrierter die Silbernitratlösung ist and je länger das Objeki damit behandelt wird, un so dicker erscheinen die Versilberungshilder.

Weil das Silberbild nach dieser Methode nicht rein schwarz, sondern violettschwarz erscheint, muß das Gold sich im Silberloild hinzugeselli. haben. Die Silberimprägnierung in den Mitochondrien nach meiner Methode vollaieht sich wahrscheinlich in der Weise, daß anfangs das Goldchlorid sich gleichmäßig sehr diunn in den Zellen des Schnittes verteilt, welches aher bei dem tinlegen des Schnities in dor Silbernitralösung ans lockerer gebauten strukturen rasch ausgeht, aber in den dichter gebauten Mitochondrien länger bleibt. Wenn die Silberionen in die Mitochondrien eindringen, verbinden sie sich mil den Chlorionen des Goldchlorides, und das entstandene unlösliche Silberchlorid setzt sich ab. Im Inneren der Mitochondl:ien koexistieren nun die gelösten Gold-und Silberionen. Durch Zusat\% des Reduktionsmittels werden die Gold- und Silberionen reduziert und in metallisches Gold und Silder umgewandelt. Darauf, daf.s das naszierende metallische Silber sich besonders leicht und reichlich an der Oberfläche der Silberchloridniederschläge ablagert, hat schon SEKI (1940) hingewiesen. Mit der Zeit vermehrt sich die Ablagerung des Silbers, daher wird das Silberbild der Mitochondrien dicker. Ob und wie das Wechselspiel von Gold und Silber dabei ror sich geht, muss noch dahingestellt bleiben.

\section{Zusammenfassung.}

Es wurden Paraffinschnitte von den mit der REGACDschen Flïssig- 
keit fixierten Gewebstiickchen nach der Vorbehandlung mit einer sehr verdünten Goldchloridlösung mit einer Silbernitratlösung ïberdeckt und dann mit einem Gelatine. $\mathrm{H}$ rdrochinongemisch reduziert. Die Mitochondrien in den Zellen tingierten sich sehr elektiv violettschwarz. Die Resultate der Versilberung nach dieser Methode an verschiedenen Organen sind mit Jhotographien gezeigti.

\section{内 容 自抄.}

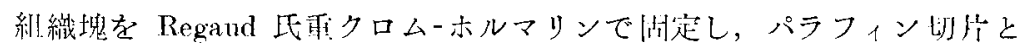

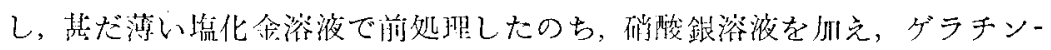

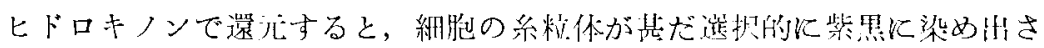

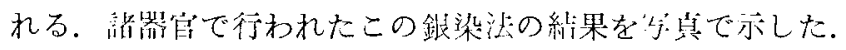

\section{Literatur.}

Arnold, G. : The role of the chondriosomes in the cells of the guineapig's pancreas. Arch. Zellforsch. 8 (1912). - Benda, C.: Die Mitochondria des Nierenepithels. Verh. anat. Ges. 17 (1903). - Bensley, R. R.: Studies on the pancreas of the guineapig. Amer. J. Anat. 12 (1911). - Eklï, H.: Chondriosomenstudien an den Epithel- und Drüsenzellen des Magen-Darmkanals und den Ösophagusdrüsenzellen bej Säugetieren. Anat. H. 51 (1914). - Fukuda, E. : Studien über die feinere innere Zellstruktur der Fibroblasten aus Gewebeskulturen in vitro. (Jap. m. dtsch. Zfass.) Kaibo Z. 16 (1940). - Inoue, K.: Zytologische Intersuchung der Belegzellen der Magen-Fundusdrüsen. IV. Beobachtung an dep Ratte von der Geburt bis zur Reife. (Jap. m. dtsch. Zfass.) Kaibo Z. 9 (1936). - Kato, K.: Fein-histologische Veränderungen der Schleimepithel in der Pubertät, Schwangerschaft und dem Puerperiumstadium. (Jap.) Kaibo Z. 2 (1929). - Kolmer, W.: Uber einige durch Ramon y Cajals Tran-Silbermethode darstellbare Strukturen und deren Bedeutung. Anat. Anz. 48 (1916). - Kolster, R.: Mitochondria und Sekretion in den Tubuli contorti der Niere. Beitr. path. Anat. 51 (1911). -

Kon, Y. u. K. Takeda : Silberreaktion der endokrinen Drüsen und Histochemie. Tokyo, 1937. - Matsuda, T.: Eine Methode zur Darstellung der Plascosomen durch Silberimprägnationsmethode. (Jap.) Osaka Iji Shinshi. 7 (1936). - Mislawsky, A. N.: Beitrigge zur Morphologie der Drüsenzelle. Über das Chondriom der Pancreaszelle einiger Nager. Anat. Anz. 39 (1911). - líber die Chondriom der Pancreaszellen. Arch. mikr. Anat. 81 (1913). -- Miyoshi, R. : Zytologische Entersuchung der Nirenepithelzellen. (Jap. m. dtsch. Zfass.) Kaibo Z. 9 (1936). Noë1, R. : Sur quelques données relatives à l'histophysiologie du foi, et leur importance possible dans la pathologie hépatique. J. Med. Lyon. 1923. - Okanishi, J.: Studies on the mitochondria and metachondria of the gastric gland cells. I. The mitochondria and metachondria of the fundus gland cells. Jap. J. of exper. Hed. 11 (1933). - Ogawa, M. : Zytologische Lntersuchungen des Iterusepithels von Ratte. (Jap.) Kaibo Z. 7 (1934). - Schlutze, O.: Cber die Genese der Granula in den Drüsenzellen. Anat. Anz. 38 (1911). — Seki, M.: 
Zur Theorie der histologischen Silberschwarzung. I. Z. Zellforsch, 30 (1940).

Sekine, M. : Studien über die Mitochondrien und Metachondrien in den Speicherdrüsenzellen (Parotis und Submandibulardrüse). (Jap.) Jikken Igaku Z. 21 (1937). - Sunaga,Y.: Cytological studies on the renal corpusele and the proximal convolution of the renal tubulus in the human kedney. I. Cytological observation of the epithelium of the proximal convolution. (Jap. m. eng. Zfass.) Arch. hist. jap. 8 (1955). - Takagi, K.: Untersuchungen über die Unterkieferdrüse der Katze mit hesonderer Berücksichtigung des Chondrioms. Z. mikr. anat. Forsch. 2 (1925). - Tanaka, R.: Vergleichende Untersuchung über die Zellgranula nach verschiedenen Versilberungsmethoden. (Jap.) Trans. Soc. path. jap. 17 (1927). - Tomita, T.: Über eine in unserem Institut erfundene Versilberungsmethode und jhre Anwendung. Jap. J. of Med. Soi. I. Anat. 8 (1941). Z Zimmermann, K. W. : Beiträge zur Kenntnis einiger Drüsen und Epithelien. Arch. mikr. Anat. 52 (1898). 